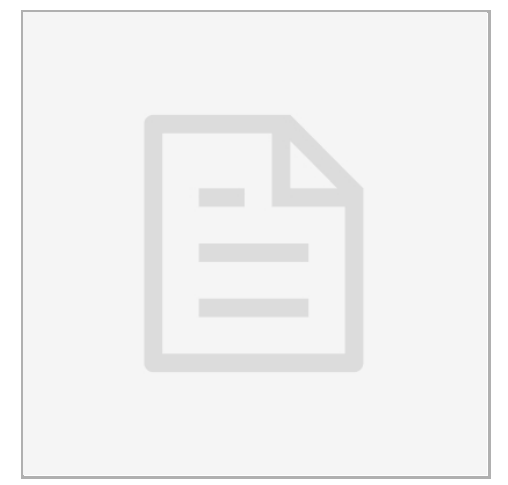

VERSION 1

SEP 11, 2019

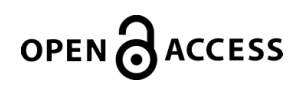

DOI:

dx.doi.org/10.17504/protocol s.io.664hhgw

Protocol Citation: Mikyeong Cho, Hyeonkyeong Lee1*, Young-Me Lee2, Ja-yin Lee1, Haeyoung Min3, Youlim Kim1, Sookyung Kim1 2019.

Psychometric Properties of the Korean Version of the Health Literacy on Social

Determinants of Health Questionnaire (K-HL-SDHQ). protocols.io

https://dx.doi.org/10.17504/p rotocols.io.664hhgw

License: This is an open access protocol distributed under the terms of the Creative Commons Attribution License, which permits unrestricted use, distribution, and reproduction in any medium, provided the original author and source are credited

Protocol status: Working We use this protocol and it's working

Created: Sep 08, 2019

Last Modified: Sep 11, 2019

\section{(3) Psychometric Properties of the Korean Version of the Health Literacy on Social Determinants of Health Questionnaire (K-HL-SDHQ) V.1}

Mikyeong Cho ${ }^{1}$, Hyeonkyeong Lee1*1, Young-Me Lee2², Ja-yin Lee1 ${ }^{1}$, Haeyoung Min33 ${ }^{3}$, Youlim Kim1 ${ }^{1}$, Sookyung Kim1

${ }^{1} 1$ Mo-Im Kim Nursing Research institute, College of Nursing, Yonsei University, Seoul, Korea;

22 School of Nursing, DePaul University, Chicago, Illinois, United States of America;

33 College of Nursing, Gyeongsang National University, Jinju, South Korea Mikyeong Cho 
PROTOCOL integer ID:

27580 